\title{
Testosterone during Puberty Shifts Emotional Control from Pulvinar to Anterior Prefrontal Cortex
}

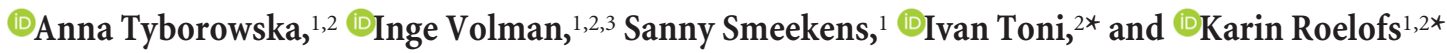 \\ ${ }^{1}$ Behavioural Science Institute, Radboud University Nijmegen, 6525 HR Nijmegen, The Netherlands, ${ }^{2}$ Donders Institute for Brain, Cognition and Behaviour, \\ Radboud University Nijmegen, 6525 EN Nijmegen, The Netherlands, and ${ }^{3}$ Sobell Department of Motor Neuroscience and Movement Disorders, UCL \\ Institute of Neurology, University College London, London WC1E 6BT, United Kingdom
}

Increased limbic and striatal activation in adolescence has been attributed to a relative delay in the maturation of prefrontal areas, resulting in the increase of impulsive reward-seeking behaviors that are often observed during puberty. However, it remains unclear whether and how this general developmental pattern applies to the control of social emotional actions, a fundamental adult skill refined during adolescence. This domain of control pertains to decisions involving emotional responses. When faced with a social emotional challenge (e.g., an angry face), we can follow automatic response tendencies and avoid the challenge or exert control over those tendencies by selecting an alternative action. Using an fMRI-adapted social approach-avoidance task, this study identifies how the neural regulation of emotional action control changes as a function of human pubertal development in 14-year-old adolescents $(n=47)$. Pubertal maturation, indexed by testosterone levels, shifted neural regulation of emotional actions from the pulvinar nucleus of the thalamus and the amygdala to the anterior prefrontal cortex (aPFC). Adolescents with more advanced pubertal maturation showed greater aPFC activity when controlling their emotional action tendencies, reproducing the same pattern consistently observed in adults. In contrast, adolescents of the same age, but with less advanced pubertal maturation, showed greater pulvinar and amygdala activity when exerting similarly effective emotional control. These findings qualify how, in the domain of social emotional actions, executive control shifts from subcortical to prefrontal structures during pubertal development. The pulvinar and the amygdala are suggested as the ontogenetic precursors of the mature control system centered on the anterior prefrontal cortex.

Key words: adolescence; approach-avoidance task; fMRI; frontal pole; hormones; thalamus

\section{Significance Statement}

Adolescents can show distinct behavioral problems when emotionally aroused. This could be related to later development of frontal regions compared with deeper brain structures. This study found that when the control of emotional actions needs to be exerted, more mature adolescents, similar to adults, recruit the anterior prefrontal cortex (aPFC). Less mature adolescents recruit specific subcortical regions, namely the pulvinar and amygdala. These findings identify the subcortical pulvino-amygdalar pathway as a relevant precursor of a mature aPFC emotional control system, opening the way for a neurobiological understanding of how emotion control-related disorders emerge during puberty.

\section{Introduction}

Adolescence is often characterized by reward- and sensationseeking behaviors (Steinberg et al., 2008; Harden and Tucker-

\footnotetext{
Received Oct. 26, 2015; revised March 6, 2016; accepted April 3, 2016.

Author contributions: I.V., I.T., and K.R. designed research; S.S. performed research; A.T. and I.V. analyzed data; A.T., I.V., I.T., and K.R. wrote the paper.

This work was supported by a starting grant from the European Research Council (Grant ERC_StG2012_313749) and Vici Grant 453-12-001 from the Netherlands Organisation for Scientific Research awarded to K.R. I.T. was supported by Vici Grant 453-08-002 from the Netherlands Organisation for Scientific Research.

*I.T. and K.R. share senior authorship.

The authors declare no competing financial interests.

Correspondence should be addressed to Anna Tyborowska, Kapittelweg 29, 6525 EN Nijmegen, P.0. Box 9101, 6500 HB Nijmegen, The Netherlands. E-mail: a.tyborowska@donders.ru.nl.

S. Smeekens' present address: Faculty of Psychology and Educational Sciences, Open University of the Netherlands, 6401 DL Heerlen, The Netherlands.
}

Drob, 2011). The increased occurrence of those behaviors during puberty has been linked to a relative imbalance in the maturation of prefrontal areas compared with already well developed striatal structures, resulting in reduced goal-directed control during decision-making processes (Braams et al., 2015; Defoe et al., 2015). However, it remains unclear whether developmental imbalances in the same frontostriatal circuits are also responsible for the altered control of emotional action tendencies observed during puberty (Ernst and Fudge, 2009). This study addresses the largely unexplored issue of how emotional action control is neurally implemented during puberty. 
We know that, in adults, the lateral anterior prefrontal cortex (aPFC; also known as lateral frontal pole; Neubert et al., 2014) plays a crucial role in emotional action control by downregulating emotional action tendencies in the amygdala (Volman et al., 2011a, 2013). However, the aPFC and its connections to limbic structures develop relatively late in puberty (Tamnes et al., 2010). During that phase, emotional control might be coordinated by a number of subcortical structures showing faster maturation and strong responses to emotional processing. In addition to well known contributions from the amygdala and the striatum (Pfeifer et al., 2011; Scherf et al., 2013), recent work has shown that the dorsomedial pulvinar nucleus of the thalamus is necessary for emotional processing (Ward et al., 2007). Namely, by virtue of the colliculo-pulvino-amygdalar pathway (Morris et al., 1999; Tamietto et al., 2012) and its extensive connectivity with frontoparietal areas (Arcaro et al., 2015), the dorsomedial pulvinar is well placed for providing an alternative pathway to the frontalamygdalar circuit controlling emotional action tendencies in adults (Arend et al., 2015; Barron et al., 2015). The neurophysiological properties of the pulvinar support this possibility, including rapid neuronal responses to visual facial features (Nguyen et al., 2013a), and a coordinating role across frontal, parietal, and temporal areas during movement selection (Wilke et al., 2010; Saalmann et al., 2012). However, it remains unclear whether and how the pulvinar is involved in emotional processing when the aPFC is not yet sufficiently mature to implement flexible goal-directed control of emotional action tendencies.

Here we address this issue by exploiting a task that has repeatedly been shown to robustly capture behavioral and cerebral correlates of emotional control (Rinck and Becker, 2007; Roelofs et al., 2009a; Volman et al., 2011a,b, 2013). The approachavoidance (AA) task requires participants to evaluate the emotional expression (happy, angry) of faces and to respond by either pulling a joystick toward (approach) or away (avoidance) from themselves. Affect-congruent conditions involve automatic stimulus-response mappings (i.e., approach-happy and avoid-angry faces). In contrast, affect-incongruent conditions require participants to apply emotional control, namely, to override those emotional action tendencies and select an alternative action to meet task demands (approach-angry and avoid-happy faces) (Fig. 1). We use this task in a group of 14-year-old adolescents. This age marks a pubertal stage when sexual maturation is completing in both sexes, but behavioral, emotional, and cerebral development can still widely differ among individuals (Giedd et al., 1999; Crone et al., 2008; Monahan and Steinberg, 2011). Accordingly, we quantify pubertal development with an endogenous physiological marker, salivary testosterone, that is sensitive to those interindividual differences (Giedd et al., 2006; Forbes and Dahl, 2010; Berenbaum and Beltz, 2011) and is mechanistically involved in mediating neural development (Sisk and Zehr, 2005; Nguyen et al., 2013b; Herting et al., 2014). We expect that relatively less mature 14-year-old adolescents control their emotional action tendencies by relying on a pulvino-amygdalar system. In contrast, developmentally more advanced 14-year-old adolescents might be able to access the prefrontal-amygdalar control system used by adults (Volman et al., 2011a).

\section{Materials and Methods}

Participants. Forty-nine 14-year-old right-handed adolescents (Table 1) participated in the study. All participants had normal or corrected-tonormal vision, no history of psychiatric disorders or neurological illness (as indicated by parent/guardian report). Participants were recruited from the Nijmegen Longitudinal Study on Infant and Child Develop-

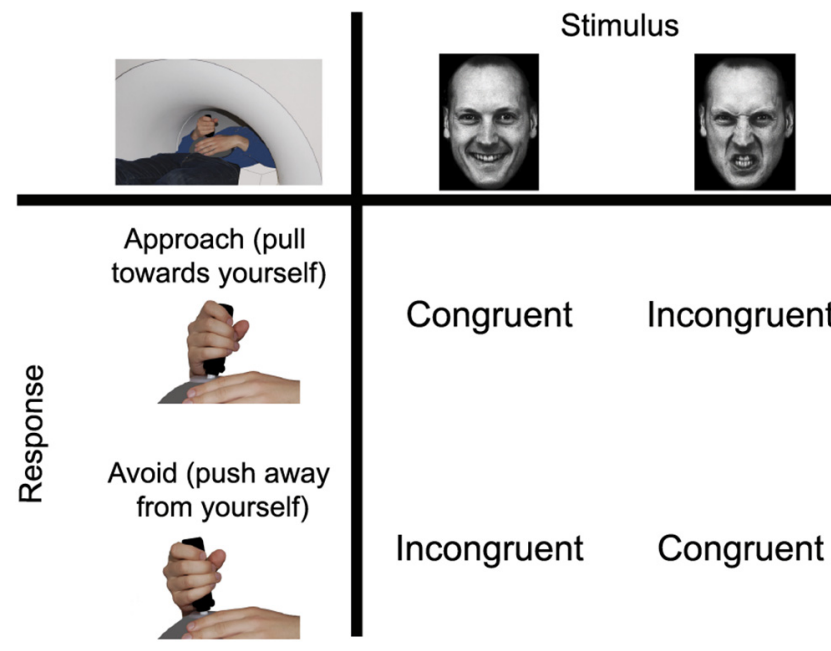

Figure 1. Approach-avoidance task (Volman et al., 2011a, 2013). The response action to an emotional face is associated with an approach (pull toward) or avoidance (pull away) movement and can be either congruent or incongruent with the automatic tendency elicited by the face. Affect-congruent conditions (approach- happy, avoid-angry) overlap with the automatic tendency to approach something positive and avoid something negative. However, during affect-incongruent conditions these emotional tendencies need to be controlled to perform the opposite action (avoid-happy, approach-angry).

Table 1. Demographic information: testosterone levels, PDS, and age per gender

\begin{tabular}{llcll}
\hline & Testosterone T1 $(\mathrm{pg} / \mathrm{ml})$ & Testosterone T2 $(\mathrm{pg} / \mathrm{ml})$ & PDS score & Age (years) \\
\hline Boys & $39.4(31.53)$ & $42.2(24.77)$ & $2.4(0.63)$ & $14.55(0.10)$ \\
Girls & $10.7(6.28)$ & $11.66(9.25)$ & $2.6(1.02)$ & $14.61(0.18)$ \\
\hline
\end{tabular}

Values represent the mean (SD). Testosterone $\mathrm{T} 1$ and $\mathrm{T} 2$ represent the first and second salivary measurement (respectively). Testosterone values between the first and second measurement did not differ significantly either for boys $\left(t_{(19)}=-0.99, p=0.333\right)$ or girls $\left(t_{(25)}=-0.66, p=0.514\right)$. Testosterone T1 levels were used for subsequent analyses.

ment. Two participants were excluded due to technical problems (poor MRI image quality), resulting in 47 participants ( 21 males) who were included in the final analyses. Written informed consent was obtained from parents as well as from participants. The study was approved by the local ethics committee (CMO region Arnhem-Nijmegen, The Netherlands).

Experimental task. During the AA task, participants were presented with emotional faces, which they had to evaluate based on their affective expressions (happy, angry). They responded using a joystick, pushing it toward themselves (approach) or away from themselves (avoid). After making a response, participants had to return the joystick to its starting position (defined as the central area covering 15\% along the sagittal plane) before the end of the intertrial interval (ITI; $2-4 \mathrm{~s}$ ). If this did not happen, participants received visual feedback stating "return the joystick to the starting position"; the ITI was repeated after the joystick was returned to its correct position. Responses were considered to be valid when the joystick was displaced at least $65 \%$ along the sagittal plane and were delivered within $3 \mathrm{~s}$ following stimulus presentation. Invalid responses were signaled for $1 \mathrm{~s}$ with visual feedback indicating "you did not move your joystick far enough."

The task consisted of 16 blocks, 12 trials each. After each block, there was a baseline period (21-24 s). There were two block types/response mappings (affect congruent, affect incongruent) and four affect $\times$ response combinations, namely, happy-approach, angry-avoid (affect congruent) and happy-avoid, angry-approach (affect incongruent). At the start of each block, the participant was instructed on the required response mapping. The block type of the first block was counterbalanced across participants, with the sequential blocks always switching between the two block types. Affective expressions and gender types (of faces) were pseudorandomly and evenly distributed within each block, with no more than three consecutive presentations of each. During the training 
part of the task, four blocks were presented with eight trials each. Each block consisted of the same affect $X$ response combinations. The training phase did not contain the same visual stimuli as the experimental task.

Materials and apparatus. The fMRI data were acquired on a Siemens 3 tesla MAGNETOM Trio MRI scanner (Siemens Medical Solutions) using a 32-channel coil. The acquisition of the functional scans was performed with a multiecho echoplanar imaging (EPI) sequence (TR = $2190 \mathrm{~ms} ; \mathrm{TE}=9.3,20.9,32$, and $44 \mathrm{~ms}$; flip angle $=90^{\circ} ; 34$ transversal slices; $3.3 \times 3.3 \times 3.0 \mathrm{~mm}$ voxels; FOV $=212 \mathrm{~mm}$ ). This type of parallel imaging technique for functional images allows a significant reduction in the echo train length, which reduces motion artifacts and image distortion. It improves BOLD sensitivity, especially in brain regions that typically would be compromised by the use of a single short TE. Finally, the reduced distortion allows better coregistration of functional and anatomical data (Poser et al., 2006). Structural T1 images were acquired using an MPRAGE sequence (TR $=2300 \mathrm{~ms}$; $\mathrm{TE}=3.03 \mathrm{~ms} ; 192$ sagittal slices; $1.0 \times 1.0 \times 1.0 \mathrm{~mm}$ voxels; $\mathrm{FOV}=256 \mathrm{~mm}$ ).

An MR-compatible joystick (Fiber Optic Joystick, Current Designs), with a sampling rate of $\sim 550 \mathrm{~Hz}$, was placed on the abdomen of the participants to ensure comfortable push and pull movements. The visual stimuli consisted of faces from 36 models (18 male) taken from several databases (Ekman and Friesen, 1976; Matsumoto and Ekman, 1988; Lundqvist et al., 1998; Martinez and Benavente, 1998). Each model showed two affective expressions (happy, angry). The pictures were in grayscale, matched for brightness and contrast values, and displayed against a black background. To exclude influence from hair and nonfacial contours, the faces were trimmed (Roelofs et al., 2009a). The stimuli were projected at the center of a screen and viewed via a mirror above the subject's head, with a visual angle of $4^{\circ} \times 6^{\circ}$ (width $\times$ height). Stimuli presentation and acquisition of joystick positions were controlled by a PC running Presentation software version 10.2 (http://www.neurobs.com).

Procedure. Participants arrived at the laboratory with a parent. Before the experiment began, participants had the option of familiarizing themselves in a dummy scanner (a simulation scanner that lacks the magnetic field of the MRI scanner). Next, they completed several questionnaires dealing with mood, depression, and puberty. This was followed by the collection of saliva samples, after which the participants were positioned in the MRI scanner. The participants completed one additional nonemotional task in the MRI scanner before starting the experimental task. To familiarize them with the setup of the AA task, a short training session was completed $(10 \mathrm{~min})$. This was immediately followed by the fMRI session $(20 \mathrm{~min}$ ) and an anatomical scan $(5 \mathrm{~min})$. At the end of the fMRI session, saliva measurements were collected again, followed by two additional tasks outside the MRI scanner.

Pubertal development measures. Following Volman et al. (2011b), saliva samples for testosterone (Table 1) and cortisol measurements were collected by passive drool of $\sim 2 \mathrm{ml}$ into Salicap (IBL) containers, which were then stored at $-24^{\circ} \mathrm{C}$. Testosterone concentration was measured using a competitive chemiluminescence immunoassay (CLIA) with a sensitivity of $0.0025 \mathrm{ng} / \mathrm{mL}$ (IBL). The intra-assay and interassay coefficients are between $10 \%$ and $12 \%$. Cortisol concentration was measured using a commercially available CLIA with high sensitivity of $0.16 \mathrm{ng} / \mathrm{mL}$ (IBL). For this assay, the intra-assay and interassay coefficients are $<8 \%$. Participants were instructed to refrain from consuming any food, cigarettes, and drinks (except water) at least $1 \mathrm{~h}$ before the experiment. Testosterone levels undergo changes during the day/night cycle with the largest variations for mid-pubertal boys during the night (AlbertssonWikland et al., 1997) and peak testosterone levels for girls occurring in the early morning (Ankarberg and Norjavaara, 1999). The study design minimized the effects of those fluctuations on testosterone level estimation by sampling this hormone in duplicate, taken $2 \mathrm{~h}$ apart, after 10:00 A.M., resulting in consistent measurements across these two time points.

Participants filled out the Pubertal Development Scale (PDS; Petersen et al., 1988), a self-report questionnaire that contains questions on secondary sexual characteristics (Table 1). Participants indicated on a 4 point scale whether a physical characteristic (1) has not yet developed, (2) is slightly developed, (3) is moderately developed, and (4) is mature or that they do not know the stage of development for the given physical characteristic. Puberty scores are based on body growth, pubic hair, skin changes, voice change, and facial hair (for boys); and breast development and menarche (for girls; Petersen et al., 1988).

Behavioral analysis. The behavioral data were analyzed with Matlab 2012 (MathWorks) and SPSS Statistics 19 (IBM). To obtain a reliable measure of the movement onset, joystick movement was reconstructed from the joystick displacement measures on each trial (Volman, 2011b). Reaction time (RT) was defined as the time from picture presentation to movement onset. Trials with no response or a joystick movement in the incorrect direction were excluded from further analysis, as were trials with an extreme RT ( $<100$ and $>1500 \mathrm{~ms}$ ), an RT $>3$ SDs from the mean, and an error rate (ER) above chance level in a block (in which instance, the entire block was excluded). To correct for a skewed distribution of the RT, a log transformation was applied. Mean RTs were calculated for each level of the two experimental factors [Valence (happy, angry) and Response (approach, avoid)]. The ER (as a percentage) analysis included trials with either no response or a joystick movement in the wrong direction. Mean ERs were also calculated for each level of the two experimental factors. Log-transformed and standardized per group (boys, girls) testosterone and cortisol levels from the first salivary measures were included in the model as covariates, with testosterone as a covariate of interest (Volman et al., 2011b). A three-way repeatedmeasures multivariate ANOVA with factors Group (boys, girls), Response (approach, avoid), and Valence (happy, angry) was conducted on the RT and ER separately; with testosterone and cortisol included in the model as covariates, testosterone being a covariate of interest. The $\alpha$ level was set at $p=0.05$.

fMRI preprocessing and analysis. Functional data were preprocessed and analyzed using the Matlab toolbox SPM8 [Statistical Parametric Mapping (www.fil.ion.ucl.uk/spm)]. The first four volumes were discarded to control for T1 equilibration effects. The multiecho sequence acquired four echoes per volume at every time point. The head motion parameters were estimated on the MR images with the shortest echo time $(9.4 \mathrm{~ms})$ because these images are the least affected by possible artifacts in the multiecho GRAPPA (generalized autocalibrating partially parallel acquisition) MR sequence (Poser et al., 2006). The calculated correction parameters, estimated using a least-squares approach with six rigid-body transformation parameters (translations, rotations), were applied to the remaining echoes of the same volume. Using an optimized echoweighing method (the first 30 time points acquired before the actual experiment started), the four echoes were combined into a single volume. To correct for time differences in the acquisition of slices within a volume, the time courses of each voxel were realigned to the middle slice (slice 17). The T1-weighted image was coregistered to the mean of the functional images. Subsequently, the T1-weighted images were segmented into gray matter, white matter, and CSF using the "New Segment" tool in SPM8. To achieve more accurate spatial normalization given the relatively young age of the participants, the fMRI time series was normalized and smoothed using a group-specific template. Diffeomorphic anatomical registration through exponentiated lie algebra (DARTEL; Ashburner, 2007) was used for intersubject registration of the gray matter images. The fMRI time series was then transformed and resampled at an isotropic voxel size of $2 \mathrm{~mm}$, resulting in spatially normalized, Jacobian scaled, and smoothed ( $8 \mathrm{~mm}$ FWHM Gaussian kernel) images in Montreal Neurological Institute (MNI) space.

Multiple regression $f M R I$ analysis. The fMRI time series were analyzed in an event-related design within the general linear model. The vectors describing the onset and duration of each condition (approach-happy, approach-angry, avoid-happy, avoid-angry) were convolved with a canonical hemodynamic response function. Trials excluded from behavioral analysis were modeled with a separate regressor ("misses"), as well as those with instructions or feedback ("info"), resulting in six taskrelated regressors in the SPM multiple regression analysis. Residual head movement-related effects were modeled using the original, squared, cubic, first-order, and second-order derivatives of the movement parameters estimated with the spatial realignment procedure (Lund et al., 2005). Time courses of signal intensities of white matter, CSF, and the portion of the MR image outside the skull were included as three additional regressors. This procedure accounts for image intensity shifts due to movement of the hand within or near the magnetic field of the scanner (Verhagen et 
Table 2. Reaction times and error rates in the AA task for approach and avoidance movements in response to happy and angry faces

\begin{tabular}{lll}
\hline & Approach & Avoid \\
\hline RT (ms) & & \\
Happy & $622(16)$ & $679(16)$ \\
Angry & $673(19)$ & $679(17)$ \\
ER (\%) & & \\
Happy & $6.4(0.5)$ & $8.4(0.9)$ \\
Angry & $8.7(1.2)$ & $6.7(0.8)$ \\
\hline Valuesindicate mean (SE) across participants. & &
\end{tabular}

al., 2006). The fMRI time series were high-pass filtered (128 s cutoff), and a first-order autoregressive model was used to account for temporal autocorrelation.

Contrast images of the effects of interest (approach-happy, approachangry, avoid-happy, avoid-angry) were generated per subject and entered into a random-effects multiple regression analysis. After being log-transformed and standardized per gender, testosterone levels and cortisol levels were included in the multiple regression analysis as subject, group, and condition-specific covariates, with testosterone as a covariate of interest (Volman et al., 2011b).

In accordance with previous studies in adults (Roelofs et al., 2009a; Volman et al., 2011b, 2013), we tested for a congruency effect; here specifically, whether testosterone differentially modulated the congruency effect. The congruency effect represents the task-related differences during affect-incongruent trials (approach-angry, avoid-happy) compared with affect-congruent trials (approach-happy, avoid-angry). In addition to the whole-brain analyses, we tested for congruency effects within the aPFC and amygdala, regions that were sensitive to the congruency effect in previous studies in adults (Volman et al., 2011b, 2013). For the lateral aPFC, we used a region of interest (ROI) mask of the lateral frontal pole (lateral aPFC) taken from the frontal cortex parcellation atlas of Neubert et al. (2014). The amygdala ROI was defined on the basis of the Automated Anatomical Labeling (AAL) Atlas (Tzourio-Mazoyer et al., 2002). Activations were corrected for multiple comparisons using familywise error (FWE). Whole-brain analysis inferences were made at the cluster level $\left(p_{F W E}<0.05\right)$, based on a cluster-forming threshold of $p<0.001$ (uncorrected). For ROI analyses, a small volume correction (SVC; $p<0.05$ ) was performed. Anatomical inference was drawn by superimposing the SPM images on a standard SPM single-subject T1 template and subject-specific T1 scans standardized in MNI space.

Functional connectivity analysis. Following the fMRI results, we explored whether the subcortical-prefrontal maturational shift is also present in interregional connectivity as a function of pubertal development. We performed a psychophysical interaction (PPI) analysis (Friston et al., 1997) with the right amygdala as a seed region during the affectincongruent versus the affect-congruent conditions of the AA task (see fMRI results: Multiple regression analysis). Congruency effect scores (i.e., difference scores between affect-incongruent and affect-congruent conditions) from ERs and RTs, and testosterone levels (log-transformed) were standardized per gender and used as covariates of interest. Voxels included in the amygdala seed region were selected for each participant based on a sphere ( $8 \mathrm{~mm}$ radius) around the peak voxel of the group-level testosterone-modulated activation for the congruency effect (MNI coordinates: $26,-2,-14)$. Contrast images were generated per participant for the PPI between the seed region time courses and affect-incongruent versus affect-congruent conditions. A multiple regression analysis was performed with participant-specific contrast images and corresponding testosterone, ER, and RT congruency effect scores as group-specific regressors. Next to a whole-brain analysis, we performed an ROI analysis for the right thalamus, based on the AAL Atlas (Tzourio-Mazoyer et al., 2002). The choice of a unilateral mask was based on previous animal and human studies showing ipsilateral thalamic connections to subcortical areas, including the amygdala (Mehler, 1980; Leh et al., 2008; Tamietto et al., 2012). Given our a priori interest in this pathway, we used a mask ipsilateral to the seed region.

VBM analysis. The anatomical images were manually checked for significant anatomical abnormalities and scanner artifacts, and were aligned to the anterior commissure at the origin. Next, the anatomical images were segmented into gray matter, white matter, and CSF using the "New Segment" tool in SPM8. DARTEL (Ashburner, 2007) was used for intersubject registration of the gray matter images. The registered images were smoothed ( $8 \mathrm{~mm}$ FWHM Gaussian kernel, Jacobian scaled, threshold at 0.2 ) and transformed into MNI space. The gray matter images were entered into a second-level multiple regression analysis with testosterone (standardized and log-transformed per gender) as a covariate of interest. Gender and TBV (total gray matter and white matter volume) were included in the model as covariates of no interest. All statistical tests were performed on the voxel level, familywise error corrected for the whole brain or small volume corrected across all voxels in a region of interest. Our ROIs were those that were found to be significantly modulated by testosterone in the fMRI analysis. We used masks from the AAL atlas (Tzourio-Mazoyer et al., 2002) for the thalamus and amygdala, and the mask of the lateral frontal pole used in the fMRI analysis (Neubert et al., 2014).

\section{Results}

\section{Behavioral results}

Significant Valence $\times$ Response interactions for RTs $\left(F_{(1,43)}=\right.$ $\left.17.44, p<0.001, \eta_{p}^{2}=0.289\right)$ and ERs $\left(F_{(1,43)}=4.721, p=0.035\right.$, $\left.\eta_{p}^{2}=0.099\right)$ confirmed the AA task-congruency effects as reported previously, driven by longer reaction times and more errors for affect-incongruent compared with affect-congruent responses (Table 2). These behavioral congruency effects did not significantly interact with testosterone $\left(F_{(1,43)}=0.097, p=\right.$ $0.757)$ or gender $\left(F_{(1,43)}=0.008, p=0.928\right)$. Additionally, there were significant main effects of Valence $\left(F_{(1,43)}=38.366, p<\right.$ $0.001)$, Response $\left(F_{(1,43)}=27.46, p<0.001\right)$, Group $\left(F_{(1,43)}=\right.$ $7.352, p=0.01)$, and Testosterone $\left(F_{(1,43)}=4.745, p=0.035\right)$ for RTs. Furthermore, testosterone significantly interacted with Valence $\left(F_{(1,43)}=6.8, p=0.012\right)$ and Response $\left(F_{(1,43)}=5.018, p=\right.$ $0.03)$ on RTs, and with Valence $\left(F_{(1,43)}=5.454, p=0.024\right)$ for ERs, indicating faster responses to happy faces, faster avoidance, and more errors on angry faces in individuals with lower testos-

Table 3. Significant clusters showing a larger effect during affect-incongruent than affect-congruent trials in the approach avoidance task modulated by testosterone

\begin{tabular}{|c|c|c|c|c|c|c|c|c|}
\hline \multirow[b]{2}{*}{ Anatomical region } & \multirow[b]{2}{*}{ Side } & \multirow[b]{2}{*}{ BA } & \multirow[b]{2}{*}{ k } & \multicolumn{3}{|c|}{ MNI coordinates } & \multirow[b]{2}{*}{$p$} & \multirow[b]{2}{*}{$t$} \\
\hline & & & & $x$ & $y$ & $z$ & & \\
\hline $\begin{array}{l}\text { Positive testosterone modulation of con } \\
\text { aPFC/mid frontal orbital }\end{array}$ & $\mathrm{R}$ & $10 / 46$ & 33 & 40 & 58 & -6 & $0.04^{a}$ & 3.55 \\
\hline \multicolumn{9}{|c|}{ Negative testosterone modulation of congruency effect } \\
\hline $\begin{array}{l}\text { Dorsomedial thalamus/pulvinar } \\
\text { Anterior thalamus/caudate nucleus }\end{array}$ & $\begin{array}{l}L \\
R\end{array}$ & & 626 & -8 & -20 & 16 & $<0.001$ & 5.39 \\
\hline Hippocampus & L & 37 & 272 & -38 & -34 & -2 & 0.013 & 6.56 \\
\hline
\end{tabular}

BA, Brodmann Area; $k$, number of voxels in a cluster; $p$, FWE-corrected cluster-level value; $t, t$-statistic at the peak voxel; $R$, right; L, left; SFS, superior frontal sulcus.

${ }^{a}$ SVC over anatomically defined ROI. 

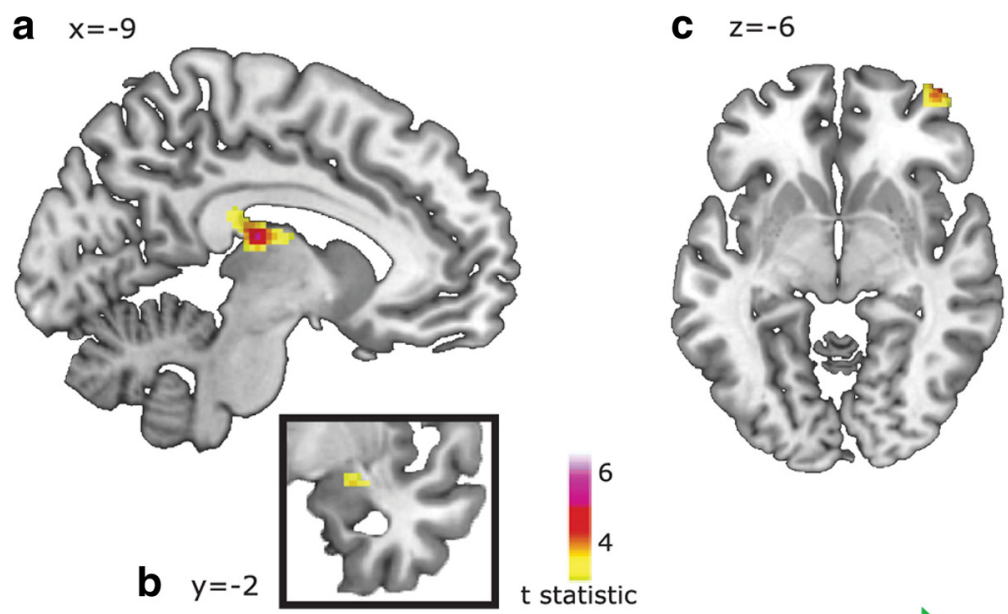

LOW

Puberty Status (Testosterone Level)

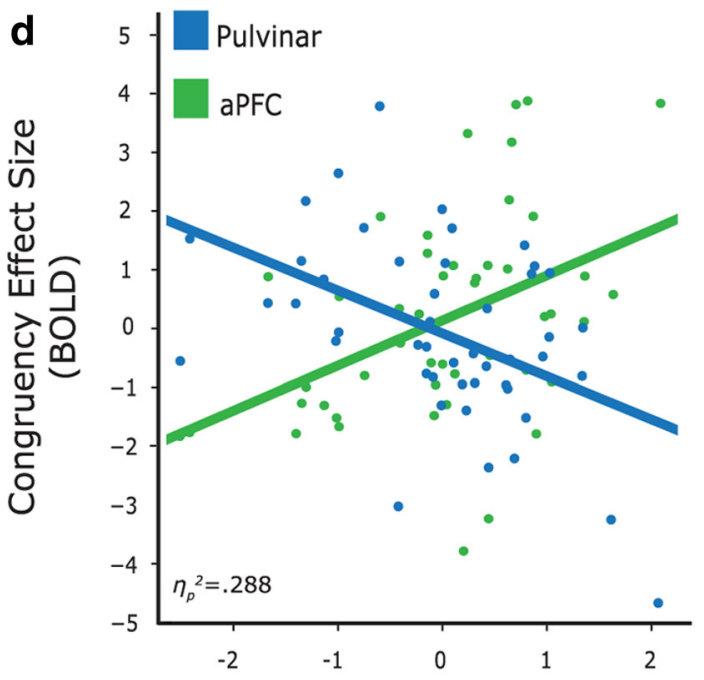

Testosterone Level Z-Scored

Figure 2. Cerebral distribution of significant testosterone-modulated congruency effects (incongruent $>$ congruent trials) across the sample of 47 participants. $\boldsymbol{a}-\boldsymbol{c}$, BOLD congruency effects decreased as testosterone levels increased in the thalamus $\left(\boldsymbol{a} ; p_{F W E}<0.05\right)$ and in the amygdala $\left(\boldsymbol{b} ; S V C p_{F W E}<0.05\right)$. BOLD congruency effects increased as testosterone levels increased in the aPFC $\left(\boldsymbol{c} ;\right.$ SVC $\left.p_{F W E}<0.05\right)$. d, Mean-adjusted BOLD congruency effects (incongruent $>$ congruent) in the aPFC (green) and pulvinar (blue) as a function of testosterone level (as an indicator of pubertal status). Dots represent the effect size of the congruency effect of each participant.

terone levels. A correlational analysis between testosterone levels and PDS scores revealed a positive relationship $(r=0.29, p=$ 0.048 ), confirming that higher testosterone levels are associated with higher puberty scores (Huang et al., 2012).

\section{fMRI results}

Multiple regression analysis

The congruency effect in the right aPFC (local maximum: 40, 58, -6) was positively modulated by testosterone, indicating that adolescents with high testosterone levels showed a stronger aPFC effect for incongruent compared with congruent trials. In contrast, the congruency effect in the thalamus (local maximum: -8 , $-20,16)$ and right amygdala (local maximum: 26, -2, -14) showed significant negative modulations by testosterone (for all effects, see Table 3). The Automated Talairach Atlas (Lancaster et al., 2000) and anatomical specifications by Arcaro et al. (2015) indicate that the activation cluster in the thalamus covered the dorsal pulvinar nucleus, the lateral dorsal nucleus, and the midline nucleus. A confirmatory ROI analysis of the pulvinar (mask extracted from the Automated Talairach Atlas) indicated a bilateral significant modulatory effect of testosterone (local maximum left: $-10,-24,16$; voxel extent: 14 ; SVC $p_{F W E}=0.028$; local maximum right: $24,-24,12$; voxel extent: 8 ; SVC $p_{F W E}=$ 0.037). In summary, individuals with high testosterone levels showed relatively stronger aPFC congruency effects, whereas participants with low testosterone levels showed relatively stronger congruency effects in the pulvinar and amygdala (Fig. 2).

Next, we verified whether those individuals who have high aPFC congruency effects are also those with low subcortical congruency effects, and vice versa. We tested for a testosteronemodulated interaction between activity in aPFC and pulvinar. A two-way repeated-measures ANOVA with factors Congruency (incongruent, congruent) and Region (aPFC, pulvinar), and with testosterone as a covariate of interest, was conducted on parameter estimate values extracted from the peak coordinates of the given regions. An additional model considered parameter estimates from the amygdala instead of the pulvinar. A significant Congruency $\times$ Region $\times$ Testosterone interaction indicated that testosterone predicted stronger aPFC congruency-related effects in those participants with weaker congruency-related effects in the pulvinar $\left(F_{(1,45)}=18.17, p<0.001, \eta_{p}^{2}=0.288\right)$ and in the amygdala $\left(F_{(1,45)}=17.72, p<0.001, \eta_{p}^{2}=0.282\right.$; Fig. $\left.2 d\right)$. Post hoc confirmatory analyses verified this effect separately within each participant gender. For both boys and girls, significant Congruency $\times$ Region $\times$ Testosterone interactions were found for parameter estimates from the aPFC-pulvinar (boys: $F_{(1,19)}=$ 6.12, $p=0.023, \eta_{p}^{2}=0.243$; girls: $F_{(1,24)}=11.94, p=0.002$, $\eta_{p}^{2}=0.332$ ) and aPFC-amygdala (boys: $F_{(1,19)}=5.02, p=0.037$, $\eta_{p}^{2}=0.209$; girls: $\left.F_{(1,24)}=13.40, p=0.001, \eta_{p}^{2}=0.358\right)$.

A VBM analysis assessed whether the fMRI effects reported above could be accounted for by brain structural differences related to pubertal development. There were no significant testosterone-related differences in gray matter in the aPFC, pulvinar, and amygdala.

\section{Functional connectivity}

We performed a post hoc analysis to test for the presence of changes in coupling between the amygdala and pulvinar during emotional action control. We conducted a psychophysiological interaction analysis, with the right amygdala as the seed region and the congruency effect as a psychological factor. Following the study by Volman et al. (2011b), the connectivity strength for incongruent versus congruent trails was evaluated as a function of testosterone and, for the purpose of the present study, was combined with task performance. The latter was indexed with the congruency effects (incongruent vs congruent trials) observed in ERs and in RTs. We tested for the combined effects of testosterone and performance on amygdala-pulvinar connectivity as indexed by testosterone and ER and by testosterone and RT. There were no significant results when searching over the whole brain. We conducted an ROI analysis using a right thalamic mask, which indicated that the connectivity strength between the right amygdala and right pulvinar (local maxima: 18, $-20,18)$ changed as a function of the combined effect of testosterone and error rates (extent: 8 voxels; SVC $p_{F W E}=0.043$ ). A confirmatory ROI analysis using a right pulvinar mask (Auto- 

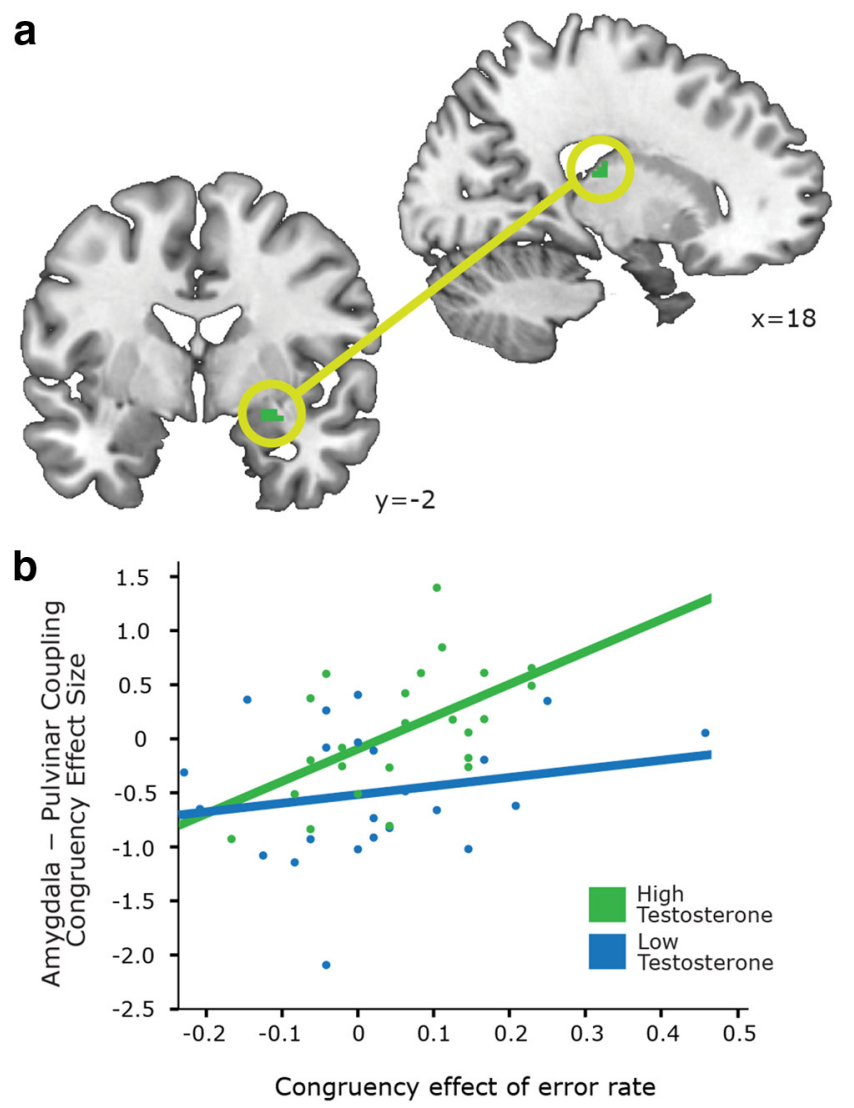

Figure 3. $\boldsymbol{a}, \boldsymbol{b}$, Functional coupling between the amygdala and pulvinar ( $\boldsymbol{a}$ ) changed as a function of performance $(\boldsymbol{b})$. Individuals with higher testosterone levels had stronger positive coupling between the amygdala and pulvinar, as a function of increasing error rate (incongruent vs congruent trials; SVC $p_{F W E}=0.043$ ). The scatterplot illustrates mean-adjusted congruency-related modulation of amygdala-pulvinar connectivity as a function of error rate, separately for high-testosterone (in green) and low-testosterone participants (in blue).

mated Talairach Atlas mask) indicated a significant effect in the right pulvinar (local maxima: 18, -24, 16; voxel extent: 3; SVC $p_{F W E}=0.022$ ). In summary, the amygdala-pulvinar connectivity of individuals with higher testosterone levels changed as a function of emotional control, namely in adolescents with higher testosterone levels, higher error rates during incongruent versus congruent trials were associated with stronger positive coupling between the amygdala and pulvinar (Fig. 3).

\section{Discussion}

This study explores the relative contribution of frontal and subcortical brain regions during emotional control in adolescence. Pubertal maturation, indexed by testosterone levels, shifted the neural control of emotional actions from subcortical regions to the aPFC. Fourteen-year-old adolescents with more advanced testosterone-indexed pubertal maturation showed greater aPFC activity when controlling their emotional action tendencies, reproducing the same pattern previously observed in adults (Volman et al., 2011a,b, 2013; Radke et al., 2015). In contrast, adolescents with less advanced testosterone-indexed pubertal maturation showed greater pulvinar and amygdala activity when exerting the same amount of control. These findings qualify and extend the notion of a developmental shift in executive control from subcortical to prefrontal regions (Blakemore, 2008; Ernst and Fudge, 2009; Crone and Dahl, 2012). Previous studies have shown similar developmental shifts from the basal ganglia and amygdala to frontal cortex in relation to motor response inhibition (Rubia et al., 2000; Stevens et al., 2007), reward sensitivity (Forbes et al., 2010; Urošević et al., 2012; Braams et al., 2015), and perceptual processing of emotional faces (Monk et al., 2003; Hare et al., 2008; Somerville et al., 2011; Barbalat et al., 2013; Vink et al., 2014). This study indicates that, when control is exerted on decisions involving emotional responses, the pulvino-amygdalar pathway may be the relevant precursor of the mature aPFC emotional control system.

\section{The pulvinar and emotional control}

The pulvinar has been relatively overlooked in human neural development studies, yet an emerging literature points to its relevance for emotion and action control. Strong afferent and efferent connections with frontal, parietal, and temporal areas make the pulvinar suitable for integrating and coordinating the selection of a broad range of goal-directed actions (Wilke et al., 2010; Saalmann et al., 2012). Furthermore, the pulvinar connects the superior colliculus with the amygdala (Morris et al., 1999; Tamietto et al., 2012), and facilitates fast emotional saliency detection and threat recognition (Ward et al., 2005, 2007; Padmala et al., 2010; Nguyen et al., 2013a). These anatomical and neurophysiological properties indicate that the pulvinar can contribute to emotional action control (Barron et al., 2015). The current study indicates that this contribution is particularly relevant during pubertal development, when frontal-striatal-thalamic coupling has yet to be completed (Stevens et al., 2007; Barbalat et al., 2013).

Recent diffusion tensor imaging studies have shown that, during early development, connectivity among subcortical structures is more prevalent than during later development (Simmonds et al., 2014; Baker et al., 2015). This study qualifies that general observation by highlighting the role of the pulvinoamygdalar pathway in the control of emotional actions at a time when the aPFC is still developing. It remains to be seen whether the amygdala facilitates the transition toward mature emotional control by incorporating social context into the processing of emotional stimuli (Scherf et al., 2013) or whether the amygdala interferes with emotional control by enhancing bottom-up sensory influences on action tendencies (Hare et al., 2005). The developmental role of the amygdala may not in fact be uniform. The centromedial amygdala shows connectivity patterns with subcortical regions, including the pulvinar, whereas the lateral basal amygdala shows connectivity patterns with prefrontal areas (Roy et al., 2009; Bzdok et al., 2013). These subdivisions of the amygdala may undergo distinct circuit changes during adolescence. The findings of this study call for further investigation of these possibilities. On the one hand, developmentally more mature adolescents (as indexed by higher testosterone levels) used the same aPFC region recruited in adults (Volman et al., 2011a,b, 2013; Radke et al., 2015). When amygdala-pulvinar connectivity was stronger during emotional control, adolescents with higher testosterone levels made more errors. This observation tentatively suggests that amygdala-pulvinar connectivity may interfere with emotional control once that function is supported by the aPFC. On the other hand, regardless of pubertal maturation, adolescents had matched performance in exerting emotional control and, as such, irrespective of aPFC or amygdala-pulvinar circuitry involvement. This observation suggests that both prefrontal and amygdala-pulvinar circuits support emotional control equally well, at least within the rather mild emotional control demands evoked by the AA task. 


\section{Interpretational issues}

Given the known differences in cerebral structure related to pubertal development and testosterone levels (Bramen et al., 2012; Nguyen et al., 2013b; Goddings et al., 2014; Urošević et al., 2014), it might be argued that the functional differences reported in this study are due to testosterone-related structural differences. However, there were no statistically significant differences in the structural features of the pulvinar, amygdala, or aPFC that were related to testosterone levels. This controlled situation is a major advantage of the current experimental design, focused on isolating puberty-related cerebral changes without generic age-related differences in executive control development.

The choice of testosterone levels as an objective and physiological marker of pubertal development is supported by previous work (Shirtcliff et al., 2009; Huang et al., 2012), and by the fact that this hormone is mechanistically involved in neuronal reorganization during adolescence (Sisk and Zehr, 2005; Schulz et al., 2009; Herting et al., 2014). The study design minimized the effects of testosterone level fluctuations (Albertsson-Wikland et al., 1997; Ankarberg and Norjavaara, 1999), as can be seen in consistent measurements across two time points, sampled $2 \mathrm{~h}$ apart. Additionally, we found that testosterone levels in our sample were positively correlated with puberty ratings for boys and girls (Shirtcliff et al., 2009). One might argue that testosterone is not only a proxy of puberty phase, but also of dominance behavior (Enter et al., 2016). However, in this study testosterone was not related to anger-approach tendencies. In fact, previous work has shown that testosterone is more closely related to physicians' ratings of pubertal maturation than self-reports, providing an objective and validated proxy of the actual pubertal stage (Huang et al., 2012).

The anatomical specificity of the emotional control effect found in the pulvinar is limited by the characteristics of the cluster-level statistics since the effect includes other structures, namely the anterior and medial thalamic nuclei and the caudate nucleus. These regions are also involved in goal-directed and stimulus-response actions (Packard and Knowlton, 2002; Ostlund and Balleine, 2008; Bradfield et al., 2013; Parnaudeau et al., 2015). Future studies might be able to differentiate among the specific contributions of those structures to emotional control in the early stages of puberty.

Based on this study, a broad extension to adolescent behavior in emotionally arousing situations is speculative and may need to be addressed with experiments where the social emotional challenge is not mild, such as the zooming version of the AA task (Heuer et al., 2007; Rinck and Becker, 2007). The zooming effect (the angry face becomes larger-approach or smaller-avoid, depending on the response) has been shown to enhance the congruency effect and is especially sensitive in capturing failures in emotion action control in various psychopathologies (Roelofs et al., 2009b, 2010; von Borries et al., 2012).

\section{Conclusion}

Developmentally more mature adolescents, in a manner similar to that of adults, recruit the aPFC during the control of emotional action tendencies, whereas less mature adolescents recruit the pulvinar and amygdala. These results are relevant for neurobiological models of pubertal development, qualifying the circuits implicated in the maturation of emotional action control. The findings are also relevant for understanding the neurobiological bases of emotion control alterations, given that the onset of affective disorders peaks during adolescence (Kessler et al., 2007). Chronic failures in emotion action control are common in vari- ous psychopathologies, such as social anxiety (Roelofs et al., 2009b, 2010) and aggression-related disorders (von Borries et al., 2012). This study opens the possibility of replicating these findings in longitudinal studies testing whether affective disorders are mechanistically related to an altered developmental transition between the pulvino-amygdalar pathway and the mature aPFC emotional control system.

\section{References}

Albertsson-Wikland K, Rosberg S, Lannering B, Dunkel L, Selstam G, Norjavaara E (1997) Twenty-four-hour profiles of luteinizing hormone, follicle-stimulating hormone, testosterone, and estradiol levels: a semilongitudinal study throughout puberty in healthy boys. J Clin Endocrinol Metab 82:541-549. CrossRef Medline

Ankarberg C, Norjavaara E (1999) Diurnal rhythm of testosterone secretion before and throughout puberty in healthy girls: correlation with 17betaestradiol and dehydroepiandrosterone sulfate. J Clin Endocrinol Metab 84:975-984. CrossRef Medline

Arcaro MJ, Pinsk MA, Kastner S (2015) The anatomical and functional organization of the human visual pulvinar. J Neurosci 35:9848-9871. CrossRef Medline

Arend I, Henik A, Okon-Singer H (2015) Dissociating emotion and attention functions in the medial pulvinar nucleus of the thalamus. Neuropsychology 29:191-196. CrossRef Medline

Ashburner J (2007) A fast diffeomorphic image registration algorithm. Neuroimage 38:95-113. CrossRef Medline

Baker ST, Lubman DI, Yücel M, Allen NB, Whittle S, Fulcher BD, Zalesky A, Fornito A (2015) Developmental changes in brain network hub connectivity in late adolescence. J Neurosci 35:9078-9087. CrossRef Medline

Barbalat G, Bazargani N, Blakemore SJ (2013) The influence of prior expectations on emotional face perception in adolescence. Cereb Cortex 23: 1542-1551. CrossRef Medline

Barron DS, Eickhoff SB, Clos M, Fox PT (2015) Human pulvinar functional organization and connectivity. Hum Brain Mapp 36:2417-2431. CrossRef Medline

Berenbaum SA, Beltz AM (2011) Sexual differentiation of human behavior: effects of prenatal and pubertal organizational hormones. Front Neuroendocrinol 32:183-200. CrossRef Medline

Blakemore SJ (2008) The social brain in adolescence. Nat Rev Neurosci 9:267-277. CrossRef Medline

Braams BR, van Duijvenvoorde AC, Peper JS, Crone EA (2015) Longitudinal changes in adolescent risk-taking: a comprehensive study of neural responses to rewards, pubertal development, and risk-taking behavior. J Neurosci 35:7226-7238. CrossRef Medline

Bradfield LA, Hart G, Balleine BW (2013) The role of the anterior, mediodorsal, and parafascicular thalamus in instrumental conditioning. Front Syst Neurosci 7:51. CrossRef Medline

Bramen JE, Hranilovich JA, Dahl RE, Chen J, Rosso C, Forbes EE, Dinov ID, Worthman CM, Sowell ER (2012) Sex matters during adolescence: testosterone-related cortical thickness maturation differs between boys and girls. PLoS One 7:e33850. CrossRef Medline

Bzdok D, Laird AR, Zilles K, Fox PT, Eickhoff SB (2013) An investigation of the structural, connectional, and functional subspecialization in the human amygdala. Hum Brain Mapp 34:3247-3266. CrossRef Medline

Crone EA, Dahl RE (2012) Understanding adolescence as a period of socialaffective engagement and goal flexibility. Nat Rev Neurosci 13:636-650. CrossRef Medline

Crone EA, Bullens L, van der Plas EA, Kijkuit EJ, Zelazo PD (2008) Developmental changes and individual differences in risk and perspective taking in adolescence. Dev Psychopathol 20:1213-1229. CrossRef Medline

Defoe IN, Dubas JS, Figner B, van Aken MA (2015) A meta-analysis on age differences in risky decision making: adolescents versus children and adults. Psychol Bull 141:48-84. CrossRef Medline

Ekman P, Friesen W (1976) Pictures of facial affect. Palo Alto, CA: Consulting Psychologist.

Enter D, Terburg D, Harrewijn A, Spinhoven P, Roelofs K (2016) Single dose testosterone administration alleviates gaze avoidance in women with social anxiety disorder. Psychoneuroendocrinology 63:26-33. CrossRef Medline

Ernst M, Fudge JL (2009) A developmental neurobiological model of motivated behavior: anatomy, connectivity and ontogeny of the triadic nodes. Neurosci Biobehav Rev 33:367-382. CrossRef Medline 
Forbes EE, Dahl RE (2010) Pubertal development and behavior: hormonal activation of social and motivational tendencies. Brain Cogn 72:66-72. CrossRef Medline

Forbes EE, Ryan ND, Phillips ML, Manuck SB, Worthman CM, Moyles DL, Tarr JA, Sciarrillo SR, Dahl RE (2010) Healthy adolescents' neural response to reward: associations with puberty, positive affect, and depressive symptoms. J Am Acad Child Adolesc Psychiatry 49:162-172.e1-e5. CrossRef Medline

Friston KJ, Buechel C, Fink GR, Morris J, Rolls E, Dolan RJ (1997) Psychophysiological and modulatory interactions in neuroimaging. Neuroimage 6:218-229. CrossRef Medline

Giedd JN, Blumenthal J, Jeffries NO, Castellanos FX, Liu H, Zijdenbos A, Paus T, Evans AC, Rapoport JL (1999) Brain development during childhood and adolescence: a longitudinal MRI study. Nat Neurosci 2:861-863. CrossRef Medline

Giedd JN, Clasen LS, Lenroot R, Greenstein D, Wallace GL, Ordaz S, Molloy EA, Blumenthal JD, Tossell JW, Stayer C, Samango-Sprouse CA, Shen D, Davatzikos C, Merke D, Chrousos GP (2006) Puberty-related influences on brain development. Mol Cell Endocrinol 254-255:154-162. CrossRef Medline

Goddings AL, Mills KL, Clasen LS, Giedd JN, Viner RM, Blakemore SJ (2014) The influence of puberty on subcortical brain development. Neuroimage 88:242-251. CrossRef Medline

Harden KP, Tucker-Drob EM (2011) Individual differences in the development of sensation seeking and impulsivity during adolescence: further evidence for a dual systems model. Dev Psychol 47:739-746. CrossRef Medline

Hare TA, Tottenham N, Davidson MC, Glover GH, Casey BJ (2005) Contributions of amygdala and striatal activity in emotion regulation. Biol Psychiatry 57:624-632. CrossRef Medline

Hare TA, Tottenham N, Galvan A, Voss HU, Glover GH, Casey BJ (2008) Biological substrates of emotional reactivity and regulation in adolescence during an emotional go-nogo task. Biol Psychiatry 63:927-934. CrossRef Medline

Herting MM, Gautam P, Spielberg JM, Kan E, Dahl RE, Sowell ER (2014) The role of testosterone and estradiol in brain volume changes across adolescence: a longitudinal structural MRI study. Hum Brain Mapp 35: 5633-5645. CrossRef Medline

Heuer K, Rinck M, Becker ES (2007) Avoidance of emotional facial expressions in social anxiety: the Approach-Avoidance Task. Behav Res Ther 45:2990-3001. CrossRef Medline

Huang B, Hillman J, Biro FM, Ding L, Dorn LD, Susman EJ (2012) Correspondence between gonadal steroid hormone concentrations and secondary sexual characteristics assessed by clinicians, adolescents, and parents. J Res Adolesc 22:381-391. CrossRef Medline

Kessler RC, Amminger GP, Aguilar-Gaxiola S, Alonso J, Lee S, Ustün TB (2007) Age of onset of mental disorders: a review of recent literature. Curr Opin Psychiatry 20:359-364. CrossRef Medline

Lancaster JL, Woldorff MG, Parsons LM, Liotti M, Freitas CS, Rainey L, Kochunov PV, Nickerson D, Mikiten SA, Fox PT (2000) Automated Talairach Atlas labels for functional brain mapping. Hum Brain Mapp 10:120-131. CrossRef Medline

Leh SE, Chakravarty MM, Ptito A (2008) The connectivity of the human pulvinar: A diffusion tensor imaging tractography study. Int J Biomed Imaging 2008;2008:789539.

Lund TE, Nørgaard MD, Rostrup E, Rowe JB, Paulson OB (2005) Motion or activity: their role in intra- and inter-subject variation in fMRI. Neuroimage 26:960-964. CrossRef Medline

Lundqvist D, Flykt A, Öhman A (1998) The Karolinska direct emotional faces (KDEF) [CD ROM]. Solna, Sweden: Department of Clinical Neuroscience, Section of Psychology, Karolinska Institute.

Martinez A, Benavente R (1998) The AR face database. Barcelona, Spain: Centre de Visioper Computador, Universitat Autónoma de Barcelona. CVC Technical Report No. 24.

Matsumoto D, Ekman P (1988) Japanese and Caucasian facial expressions of emotion (JACFEE) [slides]. San Francisco, CA: University of California, Human Interaction Laboratory.

Mehler WR (1980) Subcortical afferent connections of the amygdala in the monkey. J Comp Neurol 190:733-762. CrossRef Medline

Monahan KC, Steinberg L (2011) Accentuation of individual differences in social competence during the transition to adolescence. J Res Adolesc 21:576-585. CrossRef Medline
Monk CS, McClure EB, Nelson EE, Zarahn E, Bilder RM, Leibenluft E, Charney DS, Ernst M, Pine DS (2003) Adolescent immaturity in attentionrelated brain engagement to emotional facial expressions. Neuroimage 20:420-428. CrossRef Medline

Morris JS, Ohman A, Dolan RJ (1999) A subcortical pathway to the right amygdala mediating "unseen" fear. Proc Natl Acad Sci U S A 96:16801685. CrossRef Medline

Neubert FX, Mars RB, Thomas AG, Sallet J, Rushworth MF (2014) Comparison of human ventral frontal cortex areas for cognitive control and language with areas in monkey frontal cortex. Neuron 81:700-713. CrossRef Medline

Nguyen MN, Hori E, Matsumoto J, Tran AH, Ono T, Nishijo H (2013a) Neuronal responses to face-like stimuli in the monkey pulvinar. Eur J Neurosci 37:35-51. CrossRef Medline

Nguyen TV, McCracken J, Ducharme S, Botteron KN, Mahabir M, Johnson W, Israel M, Evans AC, Karama S (2013b) Testosterone-related cortical maturation across childhood and adolescence. Cereb Cortex 23:14241432. CrossRef Medline

Ostlund SB, Balleine BW (2008) Differential involvement of the basolateral amygdala and mediodorsal thalamus in instrumental action selection. J Neurosci 28:4398-4405. CrossRef Medline

Packard MG, Knowlton BJ (2002) Learning and memory functions of the basal ganglia. Annu Rev Neurosci 25:563-593. CrossRef Medline

Padmala S, Lim S-L, Pessoa L (2010) Pulvinar and affective significance: responses track moment-to-moment stimulus visibility. Front Hum Neurosci 4:64. CrossRef Medline

Parnaudeau S, Taylor K, Bolkan SS, Ward RD, Balsam PD, Kellendonk C (2015) Mediodorsal thalamus hypofunction impairs flexible goaldirected behavior. Biol Psychiatry 77:445-453. CrossRef Medline

Petersen AC, Crockett L, Richards M, Boxer A (1988) A self-report measure of pubertal status: reliability, validity, and initial norms. J Youth Adolesc 17:117-133. CrossRef Medline

Pfeifer JH, Masten CL, Moore WE 3rd, Oswald TM, Mazziotta JC, Iacoboni M, Dapretto M (2011) Entering adolescence: resistance to peer influence, risky behavior, and neural changes in emotion reactivity. Neuron 69:1029-1036. CrossRef Medline

Poser BA, Versluis MJ, Hoogduin JM, Norris DG (2006) BOLD contrast sensitivity enhancement and artifact reduction with multiecho EPI: parallel-acquired inhomogeneity-desensitized fMRI. Magn Reson Med 55:1227-1235. CrossRef Medline

Radke S, Volman I, Mehta P, van Son V, Enter D, Sanfey A, Toni I, de Bruijn ERA, Roelofs K (2015) Testosterone biases the amygdala toward social threat approach. Sci Adv 1:1-6. CrossRef Medline

Rinck M, Becker ES (2007) Approach and avoidance in fear of spiders. J Behav Ther Exp Psychiatry 38:105-120. CrossRef Medline

Roelofs K, Minelli A, Mars RB, van Peer J, Toni I (2009a) On the neural control of social emotional behavior. Soc Cogn Affect Neurosci 4:50-58. CrossRef Medline

Roelofs K, van Peer J, Berretty E, de Jong P, Spinhoven P, Elzinga BM (2009b) Hypothalamus-pituitary-adrenal axis hyperresponsiveness is associated with increased social avoidance behavior in social phobia. Biol Psychiatry 65:336-343. CrossRef Medline

Roelofs K, Putman P, Schouten S, Lange WG, Volman I, Rinck M (2010) Gaze direction differentially affects avoidance tendencies to happy and angry faces in socially anxious individuals. Behav Res Ther 48:290-294. CrossRef Medline

Roy AK, Shehzad Z, Margulies DS, Kelly AM, Uddin LQ, Gotimer K, Biswal BB, Castellanos FX, Milham MP (2009) Functional connectivity of the human amygdala using resting state fMRI. Neuroimage 45:614-626. CrossRef Medline

Rubia K, Overmeyer S, Taylor E, Brammer M, Williams SC, Simmons A, Andrew C, Bullmore ET (2000) Functional frontalisation with age: mapping neurodevelopmental trajectories with fMRI. Neurosci Biobehav Rev 24:13-19. CrossRef Medline

Saalmann YB, Pinsk MA, Wang L, Li X, Kastner S (2012) The pulvinar regulates information transmission between cortical areas based on attention demands. Science 337:753-756. CrossRef Medline

Scherf KS, Smyth JM, Delgado MR (2013) The amygdala: an agent of change in adolescent neural networks. Horm Behav 64:298-313. CrossRef Medline

Schulz KM, Molenda-Figueira HA, Sisk CL (2009) Back to the future: the 
organizational-activational hypothesis adapted to puberty and adolescence. Horm Behav 55:597-604. CrossRef Medline

Shirtcliff EA, Dahl RE, Pollak SD (2009) Pubertal development: correspondence between hormonal and physical development. Child Dev 80:327337. CrossRef Medline

Simmonds DJ, Hallquist MN, Asato M, Luna B (2014) Developmental stages and sex differences of white matter and behavioral development through adolescence: a longitudinal diffusion tensor imaging (DTI) study. Neuroimage 92:356-368. CrossRef Medline

Sisk CL, Zehr JL (2005) Pubertal hormones organize the adolescent brain and behavior. Front Neuroendocrinol 26:163-174. CrossRef Medline

Somerville LH, Fani N, McClure-Tone EB (2011) Behavioral and neural representation of emotional facial expressions across the lifespan. Dev Neuropsychol 36:408-428. CrossRef Medline

Steinberg L, Albert D, Cauffman E, Banich M, Graham S, Woolard J (2008) Age differences in sensation seeking and impulsivity as indexed by behavior and self-report: evidence for a dual systems model. Dev Psychol 44: 1764-1778. CrossRef Medline

Stevens MC, Kiehl KA, Pearlson GD, Calhoun VD (2007) Functional neural networks underlying response inhibition in adolescents and adults. Behav Brain Res 181:12-22. CrossRef Medline

Tamietto M, Pullens P, de Gelder B, Weiskrantz L, Goebel R (2012) Subcortical connections to human amygdala and changes following destruction of the visual cortex. Curr Biol 22:1449-1455. CrossRef Medline

Tamnes CK, Ostby Y, Fjell AM, Westlye LT, Due-Tønnessen P, Walhovd KB (2010) Brain maturation in adolescence and young adulthood: regional age-related changes in cortical thickness and white matter volume and microstructure. Cereb Cortex 20:534-548. CrossRef Medline

Tzourio-Mazoyer N, Landeau B, Papathanassiou D, Crivello F, Etard O, Delcroix N, Mazoyer B, Joliot M (2002) Automated anatomical labeling of activations in SPM using a macroscopic anatomical parcellation of the MNI MRI single-subject brain. Neuroimage 15:273-289. CrossRef Medline
Urošević S, Collins P, Muetzel R, Lim KO, Luciana M (2012) Longitudinal changes in behavioral approach system sensitivity and brain structures involved in reward processing during adolescence. Dev Psychol 48:14881500. CrossRef Medline

Urošević S, Collins P, Muetzel R, Lim KO, Luciana M (2014) Pubertal status associations with reward and threat sensitivities and subcortical brain volumes during adolescence. Brain Cogn 89:15-26. CrossRef Medline

Verhagen L, Grol M, Dijkerman H, Toni I (2006) Studying visually-guided reach-to-grasp movements in an MR-environment. Neuroimage 31:S45.

Vink M, Derks JM, Hoogendam JM, Hillegers M, Kahn RS (2014) Functional differences in emotion processing during adolescence and early adulthood. Neuroimage 91:70-76. CrossRef Medline

Volman I, Roelofs K, Koch S, Verhagen L, Toni I (2011a) Anterior prefrontal cortex inhibition impairs control over social emotional actions. Curr Biol 21:1766-1770. CrossRef Medline

Volman I, Toni I, Verhagen L, Roelofs K (2011b) Endogenous testosterone modulates prefrontal-amygdala connectivity during social emotional behavior. Cereb Cortex 21:2282-2290. CrossRef Medline

Volman I, Verhagen L, den Ouden HE, Fernández G, Rijpkema M, Franke B, Toni I, Roelofs K (2013) Reduced serotonin transporter availability decreases prefrontal control of the amygdala. J Neurosci 33:8974-8979. CrossRef Medline

von Borries AKL, Volman I, de Bruijn ER, Bulten BH, Verkes RJ, Roelofs K (2012) Psychopaths lack the automatic avoidance of social threat: relation to instrumental aggression. Psychiatry Res 200:761-766. CrossRef Medline

Ward R, Danziger S, Bamford S (2005) Response to visual threat following damage to the pulvinar. Curr Biol 15:571-573. CrossRef Medline

Ward R, Calder AJ, Parker M, Arend I (2007) Emotion recognition following human pulvinar damage. Neuropsychologia 45:1973-1978. CrossRef Medline

Wilke M, Turchi J, Smith K, Mishkin M, Leopold DA (2010) Pulvinar inactivation disrupts selection of movement plans. J Neurosci 30:8650 -8659. 